DOI: $10.5216 /$ cab.v11i4.3654

\title{
PERFIL ETIOLÓGICO DA MASTITE BOVINA NA BACIA LEITEIRA DE SANTA IZABEL DO OESTE, PARANÁ
}

\author{
Lucianne Leigue dos Santos, ${ }^{1}$ Tony Franco Fogaça Pedroso² E Erica Guirro ${ }^{2}$ \\ 1. Professor auxiliar, UFPR / Campus Palotina. E-mail: lucianne.leigue@ufpr.br \\ 2. Farmacêutico-bioquímico autônomo \\ 3. Professor assistente, UFPR / Campus Palotina. Email: ericaguirro@ufpr.br
}

\section{RESUMO}

As mastites clínica ou subclínica são as principais doenças que afetam o rebanho bovino leiteiro, com impacto sobre a economia, a indústria e com reflexos na saúde pública. Considerando-se que Santa Izabel do Oeste se encontra na segunda maior bacia leiteira do Estado do Paraná e que os casos de mastite epidemiologicamente subdividem-se em ambientais ou contagiosas, buscou-se identificar os possíveis agentes etiológicos causadores das mastites bovinas, utilizando-se um método diagnóstico preliminar rápido e barato que diferenciasse estes dois tipos da enfermidade, a fim de orientar o tratamento e a profilaxia. Optou-se por duas triplacas, sendo que a triplaca I continha em cada cavidade os seguintes meios de cultura: ágar sangue; ágar bile-esculina e ágar sal manitol; a triplaca II possuía os meios ágar MacConkey; ágar Baird-Parker e ágar sabouraud-dextrose com cloranfenicol. Adicionalmente, utilizou-se um tubo com ágar sabouraud-dextrose com cloranfenicol incubado à temperatura ambiente, para pesquisa de fungos filamentosos. Observou-se que na grande maioria das amostras foram isolados Staphylococcus coagulase negativos, coliformes, Staphylococcus aureus, bacilos gram negativos não fermentadores, corinebactérias, Streptococcus spp. e Streptococcus agalactiae.

PALAVRAS-CHAVES: Coliformes, corinebactérias, estafilococos, estreptococos, mastite.

\section{ABSTRACT}

\section{ETIOLOGICAL PROFILE OF BOVINE MASTITIS FROM DAIRY FARMS OF SANTA IZABEL DO OESTE, PARANÁ, BR}

Clinical or sub-clinical mastitis are the main illnesses that affect dairy herds, with impact on the economy, the industry, and with consequence to public health. Considering that the city of Santa Izabel do Oeste is located in the second bigger milk region of Paraná state, and that mastitis cases are epidemiologically classified as ambient or contagious, the purpose of this study was to identify possible etiologic agents of bovine mastitis, by the use of a preliminary, fast and cheap diagnostic method to differentiate these types of illness, to orient treatment and prophylactic measures. Two triplates were employed. Triplate I was composed by blood agar, bile-esculine agar and mannitol-salt agar, while triplate II was composed by MacConkey agar; Baird-Parker agar and sabouraud-dextrose agar with cloranfenicol. Additionally, a tube with sabouraud-dextrose agar with cloranfenicol incubated at room temperature temperature was used for the research of filamentous moulds. It was observed that the great majority of the isolated samples had Staphylococcus coagulase negative, coliforms, Staphylococcus aureus, no-fermenters bacilli gram negative, Coryneforms, Streptococcus spp. and Streptococcus agalactiae.

KEYWORDS: Coliforms, Coryneforms Staphylococcus, Streptococcus, mastitis. 


\section{INTRODUÇÃO}

A inflamação da glândula mamária ou mastite encontra-se entre as principais doenças de bovinos leiteiros (COSTA, 2000) e causa prejuízos aos produtores, à indústria e provoca riscos à saúde pública. A mastite é considerada a doença que proporciona as maiores perdas econômicas na produção de leite e estima-se que esta doença cause prejuízo ao redor de US\$ 1,8 bilhões/ano nos EUA (NATIONAL MASTITIS COUNCIL, 1996). No Brasil, calcula-se que a alta prevalência de mastite nos rebanhos bovinos promova redução de $12 \%$ a $15 \%$ na produção anual de leite, que é de cerca de 20 bilhões de litros/ano (FONSECA \& SANTOS, 2000).

Quanto à apresentação, a mastite pode ser classificada como clínica, que é a forma na qual visualizamse as alterações no leite e no animal, ou subclínica, forma na qual a identificação requer a adoção de recursos indiretos de diagnóstico (COSTA, 2000). A ausência de visualização direta da mastite subclínica favorece sua disseminação no rebanho e proporciona ao produtor uma falsa tranquilidade em relação à ocorrência da enfermidade, visto que é estimado que existam 35 casos subclínicos de mastite para cada caso clínico (FONSECA \& SANTOS, 2000). A mastite bovina, frequentemente, tem origem bacteriana (COSTA et al., 1995; NATIONAL MASTITIS COUNCIL, 1996; LANGONI et al., 1998) e, dentre os mais de oitenta microrganismos diferentes identificados como causadores desta enfermidade, as espécies mais frequentemente isoladas são Staphylococcus aureus, Streptococcus agalactiae, Streptococcus dysgalactiae, Streptococcus uberis e Escherichia coli (HARMON, 1994).

Acredita-se que, nos rebanhos leiteiros que não adotam medidas de controle contra mastite, haja infecção em metade das vacas, com média de dois quartos mamários por animal (NATIONAL MASTITIS COUNCIL, 1996). As estimativas brasileiras apontam valores de 20\% (LANGENEGGER et al., 1970), 38\% (FONSECA \& SANTOS, 2000) e até 71\% (COSTA et al., 1999) para a prevalência da doença em rebanhos dos estados de Minas Gerais e São Paulo.

O exame microbiológico de amostras de leite coletadas assepticamente é considerado o método padrão para determinação da saúde do úbere e para o diagnóstico da mastite bovina (RADOSTITIS et al., 1994).
Para tanto, procedimentos padronizados sugeridos pela Federação Internacional de Laticínios e Conselho Nacional de Mastite são adotados em diversos países do mundo (HARMON et al., 1990) e os resultados permitem compreender problemas específicos dos rebanhos, orientar medidas racionais de controle da mastite e sugerir mudanças de manejo (RADOSTITIS et al., 1994; BRAMLEY et al., 1996).

Existem diversas metodologias quanto à coleta de amostras de leite para avaliação da prevalência de mastite num rebanho. Pode-se avaliar o leite de todas as vacas em lactação, somente dos casos clínicos ou dos quartos mamários com contagens de células somáticas elevadas segundo o California Mastitis Test (SEARS et al., 1993; BRAMLEY et al., 1996), sendo também possível investigar amostras compostas dos quatro quartos mamários de uma vaca, ou obter amostras de leite do tanque da fazenda (SEARS et al., 1993; BRITO et al., 1998). A avaliação do leite do tanque atende programas de monitoramento de rebanhos, detecta a presença de patógenos específicos e reduz os custos com exames laboratoriais (SEARS et al., 1993; BRAMLEY et al., 1996).

Objetivou-se com este trabalho, isolar e identificar os principais agentes etiológicos causadores de mastite no rebanho leiteiro da região de Santa Izabel do Oeste, a fim de gerar subsídios no desenvolvimento de um sistema microbiológico que permita identificação rápida e barata dos patógenos envolvidos.

\section{MATERIAL E MÉTODOS}

Coletaram-se 427 amostras de leite na região de Santa Izabel do Oeste, no Estado do Paraná, entre agosto de 2006 e março de 2007. Os rebanhos foram selecionados ao acaso e apresentavam características diversas quanto à raça, grau de sangue, produção de leite, instalações, tipo e manejo da ordenha.

Inicialmente, o leite desses animais para avaliação foi coletado conforme o teste da caneca telada (RADOSTITS et al., 1994) e o California Mastitis Test - CMT (SCHALM \& NOORLANDER, 1957). $\mathrm{O}$ uso da caneca telada permite identificar os casos de mastite clínica conforme a presença de secreção anormal (flocos, grumos ou anormalidade na coloração ou na consistência). O CMT foi realizado de acordo com LANGENEGGER et al. (1970), classificando-se a 
reação inflamatória de acordo com os escores 1 (negativo), 2 (traço que indica reação suspeita), 3 (fracamente positivo, + ), 4 (positivo, ++ ) ou 5 (fortemente positivo, +++ ). A variação de escores 3 a 5 depende da consistência do gel formado pela adição do reagente ao leite e tais escores são os que melhor indicam a presença de mastite subclínica (BRITO et al., 1996).

Foram coletadas amostras de leite de todos os quartos mamários com mastite clínica ou mastite subclínica que apresentaram escore de 3 a 5 segundo o CMT. As amostras foram obtidas imediatamente antes da ordenha após cuidadosa higienização e desinfecção dos tetos com álcool 70\%. Após desprezar os três primeiros jatos de leite, coletaram-se os jatos seguintes diretamente em frascos estéreis e descartáveis, que foram colocados em caixas isotérmicas com gelo e encaminhados imediatamente ao laboratório para realização do exame microbiológico (HARMON et al., 1990).

Utilizaram-se duas triplacas, sendo que em cada uma semearam-se $10 \mu \mathrm{L}$ de cada amostra de leite, com alça calibrada e descartável, em cada um dos quadrantes (NATIONAL MASTITIS COUNCIL, 1996). $\mathrm{Na}$ triplaca I, em cada cavidade havia ágar sangue de carneiro 5\%, ágar bile esculina e ágar sal manitol. $\mathrm{Na}$ triplaca II, em cada cavidade havia ágar Baird-Parker com gema de ovo e telurito, ágar MacConkey e ágar sabouraud-dextrose com cloranfenicol. As triplacas I e II foram incubadas a $35^{\circ} \mathrm{C}$ e realizou-se leitura das triplacas após 24 e 48 horas.

As colônias isoladas no ágar-sangue foram observadas quanto à morfologia, tamanho, pigmentação e presença de hemólise. Observaram-se os microrganismos isolados ao microscópio por meio de esfregaços corados pelo método de Gram. A significância do número de colônias dos microrganismos isolados foi interpretada segundo os critérios propostos pelo NATIONAL MASTITIS COUNCIL (1987).

As bactérias do gênero Streptococcus foram identificadas conforme a ausência de produção de catalase, testes de CAMP, hidrólise do hipurato de sódio, crescimento em $\mathrm{NaCl} 6,5 \%$, produção de pyrrolidonilarilamidase e hidrólise da esculina. Fez-se a classificação de acordo com HOBLET et al. (1986), que dividem os Streptococcus em S. agalactiae (reação positiva nos testes de CAMP e hidrólise do hipurato de sódio, crescimento variável em $\mathrm{NaCl}$ 6,5\% e reação negativa na hidrólise da esculina), Streptococcus sp. esculina positivos (reação variável no teste de CAMP, na hidrólise do hipurato, em $\mathrm{NaCl} 6,5 \%$ e hidrólise da esculina, o que inclui $S$. uberis, $S$. bovis, espécies de Enterococcus e outros Streptococcus que hidrolisam a esculina) e Streptococcus sp. esculina negativos (reação negativa no teste de CAMP, na hidrólise da esculina e do hipurato de sódio e ausência de crescimento em $\mathrm{NaCl} 6,5 \%$, o que inclui $S$. dysgalactiae entre outros).

As bactérias do gênero Staphylococcus foram classificadas com base nos testes de resistência à bacitracina e na produção de catalase (SCHLEIFER \& KLOOS, 1975; BAKER, 1984; BAKER et al., 1986; KLOOS \& BANNERMAN, 1995).

O teste de produção de coagulase foi feito em tubos e em lâminas, com plasma de coelho em EDTA, de acordo com HARMON et al. (1990). Para diferenciar as espécies de Staphylococcus coagulase positivos empregaram-se os testes de produção de acetoína e utilização anaeróbica do manitol (KLOOS, 1990). Detectou-se a produção de acetoína em tubos com caldo à base de peptona e glicose incubados a $37^{\circ} \mathrm{C}$ por 48 horas. Utilizaram-se $0,5 \mathrm{~mL}$ da cultura, $0,3 \mathrm{~mL}$ de $\alpha$-naftol a $5 \%(\mathrm{p} / \mathrm{v})$ em álcool absoluto e $0,1 \mathrm{~mL} \mathrm{KOH} 40 \%(\mathrm{p} / \mathrm{v})$. A utilização anaeróbica do manitol foi testada em tubos tipo eppendorf, que continham caldo púrpura de bromocresol e que foram vedados com quinze gotas de vaselina esterilizada. Avaliou-se a sensibilidade à acriflavina em placas de ágar P (PHILLIPS \& NASH, 1985) e de Baird-Parker suplementadas com emulsão de gema de ovo e telurito. Antes de verter os meios, adicionou-se solução de acriflavina até ser alcançada a concentração final de $7 \mu \mathrm{g} /$ ml(DEVRIESE, 1981). O inóculo foi uma suspensão em caldo de soja tripticaseína cultivada por dezoito horas em ágar-sangue, padronizado com o tubo $0,5 \mathrm{da}$ escala de MacFarland. Incubaram-se placas com e sem acriflavina com a mesma suspensão de cada amostra e avaliadas após 24 e 48 horas de incubação a $35^{\circ} \mathrm{C}$. Apenas as amostras que apresentaram crescimento exclusivamente nas placas sem acriflavina foram consideradas sensíveis.

Os estafilococos coagulase negativos foram identificados pelos métodos convencionais de KLOOS \& SCHLEIFER (1975), baseado no tamanho e pigmentação das colônias; crescimento aeróbico e anaeróbico; 
presença de fator de aglutinação, hemolisina, ornitina descarboxilase, urease, pyrrolidonyl-arilamidase; resistência a novobiocina e a polimixina; utilização da arginina; produção de acetoína; redução de nitratos; hidrólise de esculina; acidificação aeróbica e anaeróbica de arabinose, celobiose, frutose, glicose, lactose, maltose, manitol, manose, rafinose, ribose, sacarose, trealose e xilose.

As bactérias Gram negativas fermentadoras de lactose e oxidase negativas foram identificadas pelo sistema EPM-mili-citrato, para triagem de enterobactérias. As bactérias Gram negativas não fermentadoras de lactose foram identificadas pela reação positiva na prova da oxidase e pelo sistema NF prov-mini kit para organismo não fermentador.

Os bastonetes Gram positivos pequenos, pleomórficos e não esporulados, com morfologia semelhante a difteroides, foram identificados como Corynebacterium sp. Além disso, observaram-se características como colônias pequenas circulares $(1 \mathrm{a}$ $2 \mathrm{~mm}$ de diâmetro), esbranquiçadas ou cremosas, com superfície rugosa, visíveis somente após 48 horas. Consideraram-se contaminantes e, portanto, descartadas as amostras em que houve crescimento de três ou mais colônias diferentes no isolamento primário, sem o predomínio de nenhuma delas.

Foram incluídas como cepas controle: Pseudomonas aeruginosa (ATCC 9027), Enterobacter aerogenes (ATCC 13048), Proteus mirabilis (ATCC 25933), Escherichia coli (ATCC 8739), Enterobacter cloacae (ATCC 13047), Shigella flexneri (ATCC 12022), Klebsiella pneumoniae (13883), Staphylococcus epidermidis (ATCC 12228), Streptococcus pyogenes (ATCC 19615) e Staphylococcus aureus (ATCC 25923).

\section{RESULTADOS E DISCUSSÃO}

Os resultados dos exames microbiológicos das amostras estudadas estão apresentados nas Tabelas 1 e 2. Conforme o observado, em $10,77 \%$ das amostras não foram isolados microrganismos no exame microbiológico e em $9,13 \%$ do total ocorreu contaminação, ou seja, crescimento de três ou mais tipos diferentes de colônias. Considerando-se a possibilidade de haver isolamento de mais de um agente etiológico por amostra, o total de microrganismos isolados foi de 427.

Os Staphylococcus sp. coagulase negativos e o Corynebacterium sp. são patógenos secundários da mastite (HARMON \& LANGLOIS, 1989) e seus papéis na glândula mamária ainda são questionados. Embora apenas algumas espécies de Staphylococcus sp. coagulase negativos estejam relacionadas com a infecção mamária e a prevalência desses, pode haver influência do desinfetante empregado na limpeza dos tetos após a ordenha (HOGAN et al., 1987; WHITE et al., 1989). Atualmente, tais agentes são vistos como patógenos contagiosos emergentes (HOGAN et al., 1987; WHITE et al., 1989), sendo que os resultados do presente estudo corroboram esta informação, já que esta classe foi a mais frequentemente isolada nas amostras. $\mathrm{O}$ controle desses agentes está ligado à adoção de boas práticas de higiene e de manejo do rebanho durante a ordenha. As amostras classificadas como Corynebacterium sp. foram catalase positiva e apresentaram características morfotintoriais e coloniais típicas de C. bovis.

Outros estudos têm chamado a atenção para a elevada porcentagem de isolamento de $C$. bovis em quartos mamários, sendo muitas vezes o agente de maior prevalência no rebanho (HARMON et al., 1990). Este achado está relacionado com a ausência ou ineficiência do processo de desinfecção dos tetos após a ordenha. No Brasil, amostras de leite oriundas de quartos mamários com mastite subclínica com escore 4 ou 5 pelo CMT apresentaram prevalência de $C$. bovis de 9,23\% (LANGONI et al., 1991) a 9,71\% (FERREIRO et al., 1985) e, no caso de mastite clínica, esta prevalência atingiu $21,77 \%$ (COSTA et al., 1995).

O Staphylococcus aureus foi o patógeno primário mais frequentemente isolado $(18,70 \%)$. Ao contrário de diversos países que erradicaram o Streptococcus agalactiae, esse agente foi isolado de $3,5 \%$ das amostras com crescimento bacteriano. É fundamental que vacas que apresentem glândula mamária infectada por $S$. aureus e/ou $S$. agalactiae sejam identificadas, mesmo que não haja inflamação evidente, a fim de se estabelecer medidas de controle, visto que, dadas as características da disseminação e infecção, esses dois agentes constituem importante fonte de infecção para os rebanhos (HARMON, 1994; BRAMLEY et al., 1996). A alta frequência desses agentes etiológicos sugere que nos rebanhos avaliados não estão sendo realizadas medidas de controle da mastite eficientes. 
TABELA 1. Resultado do exame microbiológico de todos os quartos mamários de 427 amostras de leite oriundas de rebanhos localizados na bacia leiteira de Santa Izabel do Oeste, PR

\begin{tabular}{lccc}
\hline \multicolumn{1}{c}{ Microrganismo isolado } & Número de amostras & Porcentagem \\
\cline { 3 - 4 } & & Todas as amostras & $\begin{array}{c}\text { Amostras não contaminadas e } \\
\text { com crescimento }\end{array}$ \\
\hline Coliformes & 39 & 9,13 & 11,40 \\
Streptococcus agalactiae & 12 & 2,81 & 3,50 \\
Streptococcus sp. - esculina positivos & 21 & 4,92 & 6,10 \\
Streptococcus sp. - esculina negativos & 15 & 3,51 & 4,40 \\
Staphylococcus - coagulase positivos & 0 & 0 & 0,0 \\
Staphylococcus sp. - coagulase negativos & 104 & 24,36 & 30,40 \\
Staphylococcus aureus & 64 & 14,99 & 18,70 \\
Staphylococcus hyicus & 12 & 2,81 & 3,50 \\
Staphylococcus intermedius & 3 & 0,70 & 0,90 \\
Corynebacterium sp. & 29 & 6,79 & 8,50 \\
Pseudomonas sp. & 24 & 5,62 & 7,00 \\
Leveduras & 19 & 4,45 & 5,60 \\
Amostras contaminadas & 39 & 9,13 & - \\
Sem crescimento & 46 & 10,77 & - \\
Total & 427 & 100,00 & 100,00 \\
\hline
\end{tabular}

TABELA 2. Resultados obtidos na identificação das espécies de Staphylococcus sp. coagulase negativos isolados das IMI em propriedades leiteiras de Santa Izabel do Oeste, PR

\begin{tabular}{|c|c|c|c|}
\hline Quanto à novobiocina & Staphylococcus coagulase negativo & Número de amostras & Porcentagem \\
\hline \multirow{7}{*}{ Sensível } & S. chromogenes & 21 & 18,42 \\
\hline & S. epidermidis & 20 & 17,54 \\
\hline & S. haemolyticus & 2 & 1,75 \\
\hline & S. hominis & 5 & 4,39 \\
\hline & S. hyicus & 30 & 26,32 \\
\hline & S. simulans & 1 & 0,88 \\
\hline & S. warneri & 11 & 9,65 \\
\hline \multirow{6}{*}{ Resistente } & Subtotal & 90 & 78,95 \\
\hline & S. saprophyticus & 1 & 0,88 \\
\hline & S. sciuri & 2 & 1,75 \\
\hline & S. xylosus & 11 & 9,65 \\
\hline & Subtotal & 14 & 12,28 \\
\hline & Total & 104 & 100 \\
\hline
\end{tabular}

As espécies de Staphylococcus coagulase positiva ou negativa incluem, principalmente, $S$. dysgalactiae, $S$. uberis, $S$. bovis e espécies do gênero Enterococcus. O S. dysgalactiae apresenta características de patógeno contagioso e ambiental (HARMON, 1994) e, muitas vezes, no exame microbiológico é identificado pelas reações negativas na maioria dos testes. Neste estudo, ele está incluído entre as amostras que não hidrolisam a esculina. Os outros Streptococcus e os Enterococcus são considerados patógenos ambientais, pois a fonte de infecção para o rebanho é o próprio ambiente da fazenda e, assim, as medidas profiláticas envolvem o controle de patógenos no meio (HOGAN et al., 1987). 
Os coliformes Pseudomonas spp. e leveduras também são patógenos secundários de origem ambiental e seu controle se baseia em medidas higiênicosanitárias e de manejo do rebanho (HOGAN et al., 1987).

\section{CONCLUSÕES}

Diante do exposto, pode-se concluir que o método de triagem microbiológico utilizado foi satisfatório nos quesitos rapidez, custo e agentes etiológicos diagnosticados. Ademais, verifica-se que os casos de mastite bovina clínica ou subclínica presentes na região da bacia leiteira de Santa Izabel do Oeste derivam, principalmente, das falhas de higiene antes, durante e após a ordenha, já que há grande prevalência de patógenos secundários e ambientais, sendo frequente o isolamento de Staphylococcus coagulase negativo.

\section{REFERÊNCIAS}

BAKER, J. S. Comparison of various methods for the differentiation of staphylococci and micrococci. Journal of Clinical Microbiology, v. 19, p. 875-879, 1984.

BAKER, J. S.; HACKETT, M. F.; SIMARD, D. J. Variations in bacitracin susceptibility in Staphylococcus and Micrococcus species. Journal of Clinical Microbiology, v. 23, p. 963-964, 1986.

BARROW, G. I.; FELTHAM, R. K. A. Cowan and Steel's manual for the identification of medical bacteria. 3. ed. Cambridge: Cambridge University, 1995. $331 \mathrm{p}$.

BRAMLEY, A. J.; CULLOR, J. S.; ERSKINE, R. J.; FOX L. K.; HARMON, R. J.; HOGAN, J. S.; NICKERSON, S. C.; OLIVER, S. P.; SMITH, K. L.; SORDILLO, L. M Current concepts of bovine mastitis. 4. ed. Madison: National Mastitis Council, 1996. 64 p.

BRITO, J. R. F.; CALDEIRA, G. A. V.; VERNEQUE, R. S.; BRITO, M. A. V. P. Sensibilidade e especificidade do "California Mastitis Test" como recurso diagnóstico da mastite subclínica em relação à contagem de células somáticas. Pesquisa Veterinária Brasileira, v. 17, n. 2, p. 49-53, abr./jun. 1996.

BRITO, M. A. V. P.; BRITO, J. R. F.; SOUZA, H. M.; VARGAS, O. L. Avaliação da sensibilidade da cultura de leite do tanque para isolamento de agentes contagiosos da mastite bovina. Pesquisa Veterinária Brasileira, v. 18, p. 45-46, 1998.

COSTA, E. O. NAPGAMA (Série Mastite). São Paulo: Napgama, 2000. 190 p. CD ROM.
COSTA, E. O.; BENITES, N. R.; MELVILLE, P. A.; PARDO, R. B.; RIBEIRO, A. R.; WATANABE, E. T. Estudo etiológico da mastite bovina. Revista Brasileira de Medicina Veterinária, $v$. 17, p. 156-158, 1995.

COSTA, E. O.; COSTA, E. O.; RIBEIRO, A. R.; WATANABE, E. T.; SILVA, J. A. B.; GARINO, J. R. F.; BENITES, N. R.; HORIUTI, A. M. Mastite subclínica: prejuízos causados e os custos de prevenção em propriedades leiteiras. NAPGAMA, v. 2, p. 16-20, 1999.

DEVRIESE, L. A. Baird-Parker medium supplemented with acriflavine, polymyxins and sulphonamide for the selective isolation of Staphylococcus aureus from heavily contaminated materials. Journal of Applied Bacteriology, v. 50, p. 351-357, 1981.

FERREIRO, L.; FERREIRO, C. L. R.; BANGEL JR. J. J.; SOARES, H. C.; MOOJEN, V. A.; FERNANDES J. C. T. Mastite bovina na Grande Porto Alegre, RS, Brasil. 1. Agentes etiológicos isolados durante o período 1982-1985. Arquivos da Faculdade de Veterinária da UFRGS, n. 13, p. 81-88, 1985.

FERREIRO, L.; SANTOS, E. C.; SILVA, N. Ocorrência e etiologia da mastite bovina na Zona da Mata do Estado de Minas Gerais. Arquivos da Faculdade de Veterinária da UFRGS, v. 33, p. 31-37, 1981.

FONSECA, L. F. L.; SANTOS, M. V. Qualidade do leite e controle de mastite. São Paulo: Lemos Editorial, 2000. 175 p.

HARMON, R. J. Physiology of mastitis and factors affecting somatic cell counts. Journal of Dairy Science, v. 77, p. 21032112, 1994.

HARMON, R. J.; EBERHART, R. J.; JASPER, D. E.; LANGLOIS, B. E.; WILSON R. A. Microbiological procedures for the diagnosis of bovine udder infection. Arlington: National Mastitis Council, 1990. 34 p.

HARMON, R. J.; LANGLOIS, B. E. Mastitis due to coagulasenegative Staphylococcus species. Agri-Practice, v. 10, p. 29-34, 1989.

HARROP, M. H. V.; PEREIRA, L. J. V.; BRITO, J. R. F. Incidência da mastite bovina na bacia leiteira da Zona Meridional Agreste de PE. Pesquisa Agropecuária Brasileira, v. 10, p. 65-67, 1975.

HOBLET, H.; HUESTON, W. D.; ANGRICK, A. Mastitis microbiology simplified. Bovine Practice, n. 21, p. 77-78, 1986.

HOGAN, J. S.; WHITE, D. G.; PANKEY, J. W. Effects of teat dipping on intramammary infections by staphylococci other than Staphylococcus aureus. Journal of Dairy Science, v. 70, p. 873879, 1987. 
KLOOS, W. E. Systematics and the natural history of staphylococci. Journal of Applied Bacteriology, Supplement, v. 69, n. 19, p. 25S-37S, 1990.

KLOOS, W. E.; BANNERMAN, T. L. Staphylococcus and Micrococcus. In: MURRAY, P. R.; BARON, E. J.; PFALLER, M. A. et al. (Ed.). Manual of clinical microbiology. 6. ed. Washington, D. C: American Society for Microbiology, 1995. p. 282-298.

LANGENEGGER, J.; COELHO, N. M.; LANGENEGGER, C. H.; CASTRO R. P. Estudo da incidência da mastite bovina na bacia leiteira do Rio de Janeiro. Pesquisa Agropecuária Brasileira, v. 5, p. 437-440, 1970.

LANGONI, H.; DA SILVA, A. V.; CABRAL, K. G.; DOMINGUES, P. F. Aspectos etiológicos na mastite bovina. Revista Brasileira de Medicina Veterinária, v. 20, p. 204-210, 1998.

LANGONI, H.; PINTO, M. P.; DOMINGUES, P. F.; LISTONI, F. J. P Etiologia e sensibilidade bacteriana da mastite bovina. Arquivos Brasileiros de Medicina Veterinária e Zootecnia, v. 43 , p. $507-515,1991$.

MULLER, E. E.; NETO, O. H.; SOUZA JR. J. M.; MARQUES, F. A. C.; MACUCO, A. L.; GIACOMETTI, W. D. Estudo da prevalência da mastite bovina. Semina, v. 1, p. 47-48, 1978.

NADER FILHO, A.; SCHOCKEN-ITURRINO, R. P.; ROSSI JÚNIOR, O. D.; CEMBRANELLI, E. M. Prevalência e etiologia da mastite bovina na região de Ribeirão Preto, São Paulo. Pesquisa Veterinária Brasileira, v. 5, p. 53-56, 1985.
NATIONAL MASTITIS COUNCIL. Current concepts of bovine mastitis. 4. ed. Madison: NMC, 1996. 64 p.

PHILLIPS, E.; NASH, P. Culture media. In: LENNETTE, E. H.; BALOWS, A.; HAUSLER JR. W. J. et al. (Ed.). Manual of clinical microbiology. 4. ed. Washington, D. C.: American Society for Microbiology, 1985. p. 1051-1092.

RADOSTITIS, O. M.; LESLIE, K. E.; FETROW, J. Mastitis control in dairy herds. In: RADOSTITIS, O. M.; LESLIE, K. E.; FETROW, J. Herd health food animal production medicine. Philadelphia: W. B. Saunders, 1994. p. 229-276.

SCHALM, O. W.; NOORLANDER, D. O. Experimental and observation lading to development of california mastitis test. Journal of the American Veterinary Medical Association, v. 130, n. 5, p. 199-204, 1957.

SCHLEIFER, K. H.; KLOOS, W. E. A simple system for the separation of staphylococci from micrococci. Journal of Clinical Microbiology, v. 1, p. 337-338, 1975.

SEARS, P. M.; GONZÁLEZ, R. N.; WILSON, D. J. et al. Procedures for mastitis diagnosis and control. Veterinary Clinics of North America: Food Animal Practice, v. 9, p. 445-468, 1993.

WHITE, D. G.; HARMON, R. J.; MATOS, J. E. S.; LANGLOIS, B. E. Isolation and identification of coagulase-negative Staphylococcus species from bovine sites and streak canals of nulliparous heifers. Journal of Dairy Science, v. 72, p. 1886-1892, 1989. 